\title{
Knowledge Sharing Facilitators and Barriers in the Context of Group Cohesion - A Literature Review
}

\author{
Paulina M. Wojciechowska-Dzięcielak
}

\begin{abstract}
Knowledge is one of the key intangible assets that constitutes a powerful and significant capital in organization. The purpose of the paper is to present the literature review concerning knowledge sharing issues in a workplace. Author provides a review of current knowledge sharing aspects referring to the group cohesiveness and Not-Invented-Here syndrome (NIH). The paper discusses the possible barriers and facilitators influencing accessibility of organizational knowledge and constitutes the promising background for further research in the field of organizational behavior.
\end{abstract}

Index Terms-Group cohesion, knowledge sharing, Not-Invented-Here syndrome, organizational knowledge, social identity theory.

\section{INTRODUCTION}

Family members, classmates, colleagues in a workplace... They all are the people staying in interpersonal relations. According to Forsynth, a group is defined as two or more individuals who are connected to one another by social relationships [1].

Many aspects have been discussed in psychological and sociological studies concerning groups and group behavior. We may consider group status, cohesiveness, interpersonal relations, size, roles, internal regulations, ties and bonds linking the members and other specifications concerning inter- and intragroup relations [1]-[3].

Group should not be considered only as a collection of the individuals. Members of the group interact between each other, but they have a significant relation with a group itself as well. Allport mentioned that there is no psychology of groups which is not essentially and entirely a psychology of individuals [2]. On the contrary - McDougall suggests that there exists the group-mind phenomenon, which lets people in a group do the things they were not predisposed to do individually [4]. According to Zimbardo's experiment on deindividuation, the sense of anonymity pushed the students to administer electric shocks to their colleagues more easily [5]. Acting as an anonymous person can influence our behavior significantly, which corresponds to organizational behavior aspects and can create counterproductive work behavior such as: acts of aggression, hostility, sabotage, bullying, theft, hiding or consuming necessary resources and spreading rumors [6], [7].

Many years ago, Marshall indicated the significance of

Manuscript received May 11, 2019; revised August 25, 2019.

Paulina M. Wojciechowska-Dzięcielak is now with the Department of Management Systems Design, Faculty of Management, Computer Science and Finance, Wroclaw University of Economics, Wroclaw 53-413, Poland (e-mail: paulina.wojciechowska@ue.wroc.pl). capital in our lives: Capital consists in a great part of knowledge and organization (...). Knowledge is our most powerful engine of production; it enables us to subdue Nature and force her to satisfy our wants. Organization aids knowledge [8].

Knowledge sharing phenomenon creates great possibilities and advantages for organizations. Well-defined reasonable knowledge shared in good faith may be perceived as behavior that influences positively the organizational development and vigor. Thanks to its valuable significance, knowledge sharing process may be associated with organizational citizenship behavior (OCB). Researchers identify five main categories of OCB: altruism, conscientiousness, sportsmanship, courtesy and civic virtue [9]-[11]. Research showed that OCB influences knowledge sharing postures both in real and online communities [12], [13].

Unfortunately, sharing genuine, useful and valuable knowledge may constitute costly and time-consuming process. Even if it is a beneficial operation for knowledge donor, it may be effortful and uneasy for its source. Reagans and McEvily indicated the mitigating impact of cohesiveness and social ties on group prejudices and competitiveness. Social cohesion boosts individual's motivation to transfer his or her knowledge to a coworker [14].

The concepts presented in this article indicate the connection between knowledge sharing behavior and group cohesion. The paper presents the possible issues that may constitute the subject of future research.

\section{PSYCHOLOGICAL BACKGROUND}

In 1970s and 1980s Tajfel and Turner proposed the social identity theory that considers individual's self-esteem and the approach to oneself based on one's group membership [15]. According to this concept, people idealize the status of their group to enhance their own image. Impediments and stereotypes strengthen the symptoms and signs of Tajfel and Turner's theory.

People tend to categorize themselves and other people into determined group. This type of behavior is named social categorization and is manifested in identifying people and creating the specific attitude to them. Individuals usually typecast others into various social groups: Afro-Americans, Latinos, Catholics, teachers, thieves, doctors, homeless, conservatives etc. Tendency to form impressions of people is a result of subjective categorization. Consequently, people idealize and judge the members of their group gently and lightly. Social identification aspect affects imitating behavioral patterns of other group members. Finally, to upgrade their self-esteem, they may treat the in-group as 
better, stronger, more capable etc., in comparison to the out-group which they usually consider through the negative prism as worse, weaker, useless, etc. The social comparison approach causes that two or more groups competing against each other escalate the mutual differences to build up their own self-esteem and to depreciate the opponents [16]-[18].

Brewer in his optimal distinctiveness model claimed that people possess two different basic needs concerning the relationship between self-concept and membership in social groups. Firstly, humans want to belong to the specific group, so that they strive to achieve the state of assimilation and inclusion. On the other hand, people simultaneously prefer to stay individual and aim for differentiation and distinctiveness [19], [20]. Optimal distinctiveness theory explains, that individuals endeavor to keep the equilibrium of their identity needs (inclusion/assimilation and differentiation/distinctiveness) in a given social context [21]. People tend to seek for individuation when they feel too similar to others or when they are tired with undifferentiated mass of people. Consequently, when an individual feels alone and reclusive, he or she pursues the sense of assimilation and group cohesion [22], [23].

Humans tend to identify deeper with their coworkers when they work in small groups. Employees working with people that have comparable views are more eager to establish close relations with them than with the people that are completely different. To examine the concept of cohesiveness among the employees, interviewing smaller subgroups may lead to distinct conclusions, in comparison to treating the organization as a whole. People usually feel more familiar among certain group of coworkers, than with people that they do not work often with. It brings up the following question: do employees create the sense of cohesiveness to the organization as a whole or rather they feel coherent to the certain subgroup of regular associates?

\section{IDEA OF COHESIVENESS}

Attitudes and mindsets of the group members are related to group cohesiveness. Festinger considered group cohesion as the resultant of all the forces acting on members to remain in the group [24]. Group cohesion constitutes an important aspect of group dynamics and may be considered as key attribute in group performance phenomenon. Cohesiveness can be defined as a need for being a part of the group and may be understood as the degree to which members of a group are attached to one another [25]. A literature review shows that group cohesion depends on members' assimilation to own group and on the contrast comparing to the groups [26]. It means that group is more coherent when its members identify strongly with its main values, characteristics, regulations, norms and attributes.

Considering the social identity theory of Tajfel and Turner, people observe themselves through the prism of the whole group. Individual can behave differently in various situations as a member of different groups [27]. Identifying oneself as a part of the specific group, brings out the opposite aspects: us vs. them [28]. By categorizing people, we are able to create the opinions or the judgements about them. If we want to identify with a specific group, we tend to behave according to its regulations and norms, we try to assimilate.

We develop our group identification by comparing with other groups and perceiving the differences and divergences. As group members people tend to deepen the contrasts between $u s$ and them to identify with their own group and strengthen the affiliation to it. People often idealize their group by minimizing the disparities between fellow members and disregard bothersome or unpleasant situations that took place in the group. A sense of a group loyalty is an aspect accompanying the cohesiveness issue: people usually have a tendency to stay in their group despite attractive alternatives waiting for them somewhere else [28], [29].

\section{DETERMINANTS OF COHESION}

Mutual attractiveness is a factor that meaningfully influences group cohesion: people liking each other usually spend more time together, what results in their closer relation. A physical proximity gives a tendency to stay in close contact with the others. Festinger and other researchers determined that students living in the same dormitory or on the same floor, make tighter relationships than students not living next to each other [30].

Working together to achieve a common goal increases group cohesion when the undertaking is successful [3]. People concentrated on one purpose cooperate in order to achieve the positive results; and when they succeed, the bonds between them tighten even more.

The psychologist Sherif determined the direct relation between intergroup conflict and group cohesion. The higher the competition level between the opponents, the more coherent is the group. The successful undertaking results in increasing the group solidarity and unity [31].

Oyster describes the benefits coming from high cohesiveness of a group:

1) Dynamic internal communication.

2) People are more friendly towards other members in more cohesive groups and present readiness to cooperation.

3) More cohesive groups may effectively control their members and they can successfully affect their behavior and actions.

4) Cohesive groups reach their goals more efficiently.

5) The members of cohesive groups tend to be more satisfied with being a part of the group [32], [33].

Group cohesiveness is undoubtedly a positive quality defining the organization. Closeness helps its members to follow common goals and protect the group from the outer dangers. Group cohesiveness may relate to its internal communication, but the level of possible correlation needs to be examined.

\section{KNOWLEDGE SHARING PHENOMENON}

In groups people can exchange data, information and knowledge, what enhances organizational performance. Data are just raw facts that usually doesn't have a specific meaning, meanwhile information is already a processed message. Knowledge is the appropriate collection of information, such that its intent is to be useful [34]. Knowledge constitutes a 
precious piece of content that can improve the strength of an organization and its competitive advantage when used properly and shared correctly. This is an intangible asset which is unique, path dependent and hard to imitate or substitute [35].

According to Riege, it has been widely acknowledged and proved that the most important purpose of companies' sharing practices is to protect and maximize the value derived from tacit (hidden) knowledge held by employees, customers and external stakeholders [36].

To keep the precious knowledge of the employees who retire soon, the organizations should improve their knowledge sharing skills and procedures in order not to lose the useful knowledge hidden in people's heads (tacit knowledge) or buried deep documentation piles and repositories (explicit knowledge). Argote and Miron-Spektor describe knowledge transfer as very important due to distributed work arrangements, globalization, the multiunit organizational form and interorganizational issues such as mergers, acquisitions, and alliances [37]. Employees are supposed to collaborate more easily and tighter when there are positive emotions among them and when they trust each other [38]. Deepening the external relationships between employees, customers and the organization's shareholders can enchance the knowledge flow efficiency [39]. The link between group cohesion and knowledge sharing could be also considered in the context of identification with other group members both during and after the worktime.

\section{LINKS BETWEEN KNOWLEDGE SHARING AND GROUP COHESIVENESS}

The literature review showed that small and medium-sized enterprises (SMEs) possess the convenient structures to enable the easy knowledge transfer and knowledge sharing opportunities. Thanks to their small, compact size, usually single site location and closer social relationships of the employees, such organizations constitute the convenient place to develop the cohesive links between their members. When the organization grows, moves to multiple sites and creates new subgroups within the same departments, its ability to share knowledge significantly decreases. In smaller, less bureaucratic, less formal organizations with flatter organizational structure and innovative culture, the teams collaborate more efficiently and tend to form various communication flows that support knowledge sharing phenomenon [40].

On the other hand, SMEs sometimes do not have properly developed strategies concentrated on knowledge transfers. In smaller enterprises it happens, that employees are not aware of the value of their knowledge and they do not have well-organized planning or controlling systems [41]. Smaller organizations do not usually have technologically advanced tools to support their knowledge transfer succesfully, especially between departments. This issue could be examined considering various factors such as the correlation between financial outlays for technological tools and knowledge sharing efficiency in an organization. It may be also useful to determine the relation between the worktime spent using IT tools and the level of group cohesiveness.
Close relations between team members can conduce to creating the social networks and develop the sense of trust in people, what can result in effective knowledge sharing style. Also, interpersonal skills and outgoing posture can improve knowledge flow efficiency in an organization, especially when group structure is not associated with strong hierarchy or strictly formal.

Research conducted by Chiu, Hsu and Wang showed positive correlation between members' social interaction ties and the quantity of knowledge shared by people. It was noted that, the sense of social unity and group togetherness may significantly stimulate the members' intention to share knowledge and improve the amount of the transferred content. Equally, strong group identification forms proper conditions to share knowledge frequently among the coworkers [41]. Carmeli, Atwater and Levi came to a conclusion that efficient knowledge exchange between the leader and the employees improves the sense of group identification. They also emphasized the significant role of a leader in knowledge sharing process [42].

Following the group identity theory, close intragroup relations can bring various benefits such as readiness to cooperate, improving communication between group members and facilitating internal knowledge exchange [23].

Cabrera and Cabrera described knowledge sharing in the context of social dilemma considering possible costs and benefits coming from sharing one's knowledge. Putting great effort, time and money to create new knowledge and share it with associates is not always cost-effective enough to undertake similar actions in the future. An entity intuitively does everything to maximize possible benefits. If the individual calculates costs and gains of knowledge sharing, he or she will not share, if it does not pay-off [17]. To share or not to share? dilemma may be significantly influenced by personal approach and emotions. Research conducted by Matzler et al. showed that team members or team leaders being particularly conscientious, open and agreeable, are predicted to become involved in sharing process [43]. It may be useful to seek for the correlation between the strength of group cohesiveness and people's desire to share knowledge even if they get no or just a little benefit?

Concept of reciprocity may be explained as form of interaction that is centered on mutuality. It presents the act of giving and taking. The research on virtual communities showed the positive relation between reciprocity and knowledge sharing intentions [23]. Do employees tend to imitate the others and share knowledge if the other employees do?

Although group cohesiveness can affect positively relations between team members, too tight bonds inside one group can interrupt the contacts with other departments. The following phenomenon may constitute the consequence of already mentioned social comparison and social categorization process. Strong immersion in group atmosphere, norms and habits can result in developing NIH: not invented here syndrome. People tend to see the ingroup in more positive terms than they perceive the outgroup, which could be the result of ethnocentrism and bias effect [44]. Members identifying strongly with their teams usually may be skeptical towards external knowledge. Through the 
socializing process that adapts people to be a part of the group, they experience new behaviors, attitudes, work styles and norms that are (the only) acceptable in the organization. New employees are integrated into the company's structures and adjusted to the organizational policy and philosophy [45].

According to the mentioned $\mathrm{NIH}$ syndrome, people sometimes present the negative attitude towards the external knowledge identifying it with something strange, unfamiliar or even alienated. It happens that people completely demonize and reject foreign knowledge, because they find the internal knowledge as the only legitimated, safe and trusted choice [45]. The research did by Burcharth and Andrea showed that the sense of a strong corporate identity can lead to a biased perception of the external world (they compare it to a mental prison) when the employees do not appreciate the outside knowledge but they overestimate the internal one [44], [45]. To accept, adapt and incorporate external knowledge, employees need to change their beliefs and to break with routines and stereotypes [46]. People often present a negative attitude towards the out-group members if they want to manifest their group identity. The manifestation of in-group favoritism and out-group skepticism may be even stronger if two groups are perceived as similar [47].

Citing Clagett: NIH is made not born. Actually, NIH syndrome is the consequence of employee's prejudices towards the foreign knowledge. Bad experience with external resources or wrong attitude towards the unknown assets, as well as lack of proper intergroup communication, may intensify the syndrome [48]-[51]. Lichtenhalter and Ernst discussed the difference between the acquisition, accumulation and exploitation of knowledge, which can all be carried out internally or externally [52]-[54]. Knowledge may be created inside the company or absorbed and internalized from the outside. Consequently, the assets can be stored inside the company to protect the knowledge, but also it can be related with the external organizations in order to form external bases. Effectively, knowledge may be applied into familiar products and services. By contrast knowledge may be perceived as a precious good itself. Disembodied knowledge may be commercialized and sold as a finished, complex and licensed product [55]-[57].

Another definition significant to understand the problem of external knowledge assimilation, is absorptive capacity. According to Cohen and Levinthal, the mentioned issue can be understood as the awareness of external knowledge values and the ability to determine, assimilate and use it properly [58]. Usually, firms with a high absorptive capacity tend to present attitudes to external knowledge acquisition that are at least not strongly negative [59]. The strong social cohesion in the group level can facilitate the absorptive capacity of the organization when the employees motivate each other and encourage other members to participate in knowledge sharing practices [60].

Cabrera and Cabrera described the knowledge sharing friendly environment as the area creating sense of openness, showing commitment to progress and growth, leadership strength, reducing turnover and - what is also important rewarding individual participation [17]. Knowledge transfer issue creates the valuable area in organizational behavior studies concerning many aspects of the organizational life.

\section{CONCLUSION}

Knowledge sharing process constitutes a complex structure difficult to understand without conducting elaborated analysis. This phenomenon should be examined holistically taking into consideration the group specific, its size, social interactions between its members and many different characteristics. Knowledge sharing phenomenon occurs thanks to interpersonal cooperation, but sometimes group members share knowledge because they are pressured to do it or are aware of the benefits coming from knowledge exchange. People share knowledge in order to be respected, recognized, appreciated or financially praised.

On the contrary, individuals can sometimes be afraid of showing off their knowledge, especially if their employers seem to know less than the employees. To take advantage from knowledge sharing processes, every group, should be well informed about the effects that can be achieved and the benefits that could be taken from the effective knowledge sharing. Knowledge transfer can be strengthened by the sense of group cohesion if the process is driven correctly among the people aware of possible profits coming from knowledge sharing. Finally, it could be concluded that group cohesiveness could be helpful in knowledge sharing processes. For sure, the above concept demands further researches both in smaller as well as in medium-sized and large enterprises.

The review presented in this article may help managers to compose work teams taking into consideration people's individual characteristics and personal traits. Therefore, presented information should be of interest for directors to allocate missions and tasks to proper employees, considering their nature. The theoretical background and the issues discussed in the review may support the managers to identify possible barriers and obstacles that hamper knowledge sharing process.

The above review prompts to further analysis of mentioned issues and shows the direction for future research. Does cohesiveness increase result in improving the knowledge sharing effects? Does decline in turnover rate influence the effectiveness of knowledge transfer? Does the strong sense of democracy cause growth of group cohesion? Does increase of group cohesion is correlated with decrease of turnover in a workplace? Does the intense of NIH syndrome in an organization really supports knowledge transfer? These are not the only questions to be considered for further studies.

\section{CONFLICT OF INTEREST}

The author declares no conflict of interest.

\section{AUTHOR CONTRIBUTIONS}

I approved the final version.

\section{REFERENCES}

[1] D. R. Forsyth, "Group dynamics 4e," International Student Edition, Belmont, CA.: Thomson Wadsworth Publishing, 2006. 
[2] F. H. Allport, "Social psychology as a science of individual behavior and consciousness," Chapter 1 in Social Psychology, Boston: Houghton Mifflin Company, pp. 1-13, 1924.

[3] R. Brown, Group Processes: Dynamics within and between Groups, Cambridge, MA, US: Basil Blackwell, 1988.

[4] W. McDougall, "The group mind: A sketch of the principles of collective psychology with some attempt to apply them to the interpretation of national life and character," Oxford, England: Putman, 1920.

[5] P. G. Zimbardo, "The human choice: Individuation, reason, and order versus deindividuation, impulse, and chaos," Nebraska Symposium on Motivation, pp. 237-307, Lincoln: University of Nebraska, 1969

[6] P.E. Spector and S. Fox, "The stressor-emotion model of counterproductive work behavior," Counterproductive Work Behavior: Investigations of Actors and Targets, pp. 151-174, Washington, DC, US: American Psychological Association, 2005.

[7] J. Piecuch and P. Wojciechowska, "An impact of anger expression on organizational behavior - A literature review," PRZEDSIĘBIORCZOŚĆ I ZARZĄDZANIE, Wydawnictwo SAN, ISSN 2543-8190, Tom XX, Zeszyt 6, III, pp. 133-144.

[8] A. Marshall, Principles of Economics, p. 115, London: Macmillan, 1965.

[9] D. W. Organ et al., Organizational Citizenship Behavior: Its Nature, Antecedents, and Consequences, Sage Publications, Thousand Oaks, 2006.

[10] P. M. Podsakoff, S. B. MacKenzie, and C. Hui, "Organizational citizenship behaviors and managerial evaluations of employee performance: A review and suggestions for future research," Research in Personnel and Human Resources Management, vol. 11, pp. 1-40, Greenwich, CT: JAI Press, 1993.

[11] L. Ocampo et al., "A historical review of the development of organizational citizenship behavior (OCB) and its implications for the twenty-first century," Personnel Review, vol. 47, no. 4, 2018, pp. 821-862.

[12] M. M. Wasko and R. Teigland, "Public goods or virtual commons? Applying theories of public goods, social dilemmas, and collective action to electronic networks of practice," Journal of Information Technology Theory and Application, vol. 6, no. 1, pp. 25-41, 2004.

[13] C. P. Lin, "Clarifying the relationship between organizational citizenship behaviors, gender, and knowledge sharing in workplace organizations in Taiwan," Journal of Business and Psychology, vol. 22, no. 3, 241-250, 2008.

[14] R. Reagans and B. McEvily, "Network structure and knowledge transfer: The effects of cohesion and range," Admin. Sci. Quart., vol. 48, no. 2 , pp. 240-267, 2003.

[15] H. Tajfel and J. C. Turner, "An integrative theory of intergroup conflict. The social psychology of intergroup relations?" 1979.

[16] H. Tajfel, J. C. Turner, W. G. Austin, and S. Worchel, "An integrative theory of intergroup conflict," Organizational Identity: A Reader, pp. $56-65,1979$.

[17] E. F. Cabrera and A. Cabrera, "Fostering knowledge sharing through people management practices," The International Journal of Human Resource Management, vol. 16, no. 5, pp. 720-35, 2005.

[18] S. A. McLeod. (2008). Social identity theory. [Online]. Available: https://www.simplypsychology.org/social-identity-theory.html

[19] M. B. Brewer and S. Roccas, "Individual values, social identity, and optimal distinctiveness," Individual Self, Relational Self, Collective Self, pp. 219-237, New York, NY, US: Psychology Press, 2001.

[20] M. B. Brewer, "The social self: On being the same and different at the same time," Personality \& Social Psychology Bulletin, vol. 17, no. 5, pp. 475-482, 1991.

[21] G. J. Leonardelli, C. L. Pickett, and M. B. Brewer, "Optimal distinctiveness theory: A framework for social identity, social cognition, and intergroup relations," Advances in Experimental Social Psychology, vol. 43, pp. 63-113, Academic Press, 2010.

[22] D. A. Stapel and D. M. Marx, "Distinctiveness is key: How different types of self-other similarity moderate social comparison effects," Personality and Social Psychology Bulletin, vol. 33, no. 3, pp. 439-448, 2007.

[23] L. Carmeli and A. Levi, J Technol Transf., vol. 36, p. 257, 2011.

[24] L. Festinger, "Informal social communication," Psychological Review, vol. 57, pp. 271-282, 1950.

[25] L. Dyaram and T. J. Kamalanabhan, "Unearthed: The other side of group cohesiveness," J. Soc. Sci., vol. 10, no. 3, pp. 185-190, 2005.

[26] J. C. Turner, M. A. Hogg, P. J. Oakes, S. D. Reicher, and M. S. Wetherell, "Rediscovering the social group: A self-categorization theory," Cambridge, MA, US: Basil Blackwell, 1987.
[27] J. C. Turner and H. Tajfel, "The social identity theory of intergroup behavior. Psychology of intergroup relations," pp. 7-24, 1986.

[28] L. David, "Social identity theory (Tajfel, turner)," Learning Theories, December 15, 2015

[29] T. Kameda, M. Vugt, and S. Tindale, "Evolutionary group dynamics," International Encyclopedia of the Social \& Behavioral Sciences, 2015.

[30] L. Festinger, "Informal social communication," Psychological Review, vol. 57 , no. 5, pp. 271-282, 1950

[31] M. Sherif, Group Conflict and Co-operation: Their Social Psychology, DOI: 10.4324/9781315717005, 2015

[32] M. E. Shaw, Group Dynamics: The Psychology of Small Group Behavior, McGraw-Hill, 1976.

[33] C. K. Oyster, GROUPS. A User's Guide, McGraw-Hill Social Psychology Series, 1999.

[34] G. Bellinger, D. Castro, and A. Mills, Data, Information, Knowledge, and Wisdom, 2004

[35] A. Cabrera and E. F. Cabrera, "Knowledge-sharing dilemmas," Organization Studies, vol. 23, no. 5, pp. 687-710, 2002.

[36] A. Riege, "Three-dozen knowledge-sharing barriers managers must consider," Journal of Knowledge Management, vol. 9, no. 3, pp. 18-35, 2005.

[37] L. Argote and E. Miron-Spektor, "Organizational learning: From experience to knowledge," Organization Science, vol. 22, no. 5, pp. 1123-1137, 2011.

[38] V. Urch-Druskat and S. B. Wolff, "Building the emotional intelligence of groups," Harvard Business Review, vol. 79, no. 3, pp. 80-9, 2001

[39] P. Sivula, F. A. J. Bosch, and T. Elfring, "Competence-based competition: gaining knowledge from client relationships," Knowledge Management and Organizational Competence, Oxford University Press, Oxford, 2001.

[40] R. Chase, "The people factor," People Management, vol. 4, no. 2, p. 38

[41] C. M. Chiu, M. H. Hsu, and E. T. G. Wang, "Understanding knowledge sharing in virtual communities: An integration of social capital and social cognitive theories," Decision Support Systems, vol. 42, no. 3, pp. 1872-1888, 2006

[42] M. Levy, C. Loebbecke, and P. Powell, "SMEs, co-opetition and knowledge sharing: the role of information systems," European Journal of Information Systems, vol. 12, no. 1, pp. 3-17, 2003.

[43] K. Matzler, B. Renzl, T. Mooradian, G. Krogh, and J. Mueller, "Personality traits, affective commitment, documentation of knowledge, and knowledge sharing," The International Journal of Human Resource Management, vol. 22, no. 02, pp. 296-310, 2011.

[44] A. Burcharth and A. Fosfuri, "Not-invented-here: How institutionalized socialization practices affect the formation of negative attitudes toward external knowledge," Industrial and Corporate Change, vol. 24, pp. 281-305, 2015

[45] D. Antons and F.T. Piller, "Opening the black box of "not invented here": Attitudes, decision biases, and behavioral consequences," Academy of Management Perspectives, vol. 29, no. 2, pp. 193-217, 2015.

[46] K. Hussinger and A. Wastyn, "In search for the not-invented-here syndrome: the role of knowledge sources and firm success," $R \& D$ Management, vol. 46, no. S3, pp. 945-957, 2016.

[47] F. Gabarott et al., "Being similar versus being equal: intergroup similarity moderates the influence of in-group norms on discrimination and prejudice," British Psychology Journal, vol. 48, pp. 253-273, 2009.

[48] R. P. Clagett, Receptivity to Innovation - Overcoming N.I.H, p. 29, Master thesis, MIT, 1967.

[49] D. Pay, Informationsmanagement von Inno-vationen, Wiesbaden: Gabler, 1995

[50] D. Pay, "Kulturspezifische determinanten der organisation von innovationsprozessen. Zeitschrift fur Betriebswirtschaft," Erganzungsheft, vol. 1, pp. 131-167, 1989.

[51] H. Mehrwald, "Das 'not invented here'-syndrom in forschung und entwicklung," Wiesbaden: Dt. Univ.-Verl., U., 1999.

[52] U. Lichtenthaler and H. Ernst, "Attitudes to externally organising knowledge management tasks: A review, reconsideration and extension of the NIH syndrome," $R \& D$ Management, vol. 36, no. 4, pp. 367-386, 2006

[53] U. Lichtenthaler, "External commercialization of knowledge: Review and research agenda," International Journal of Management Reviews, vol. 7, pp. 231-255, 2005.

[54] H. Ernst, "Industrial research as a source of important patents," Research Policy, vol. 27, pp. 1-15, 1998.

[55] B. Mullen and R. Brown, "Ingroup bias as a function of salience, relevance and status: An integration," European Journal of Social Psychology, vol. 22, pp. 103-122, 1992. 
[56] K. A. Epstein, "Socialization practices and their consequences: The case of an innovative organization," Sloan School of Management, Massachusetts Institute of Technology. Cambridge, MA: WP\#1502-83, 1983.

[57] S. Michailova and K. Husted, "Knowledge-sharing hostility in Russian firms," California Management Review, vol. 45, pp. 59-77, 2003.

[58] W. M. Cohen and D. A. Levinthal, "Absorptive capacity: A new perspective on learning and innovation," Administrative Science Quarterly, vol. 35, issue 1, pp. 128-152, 1990.

[59] U. Lichtenthaler and H. Ernst, "Attitudes to externally organising knowledge management tasks: A review, reconsideration and extension of the NIH syndrome," $R$ and D Management, vol. 36, no. 4 , 2006.

[60] J. J. Hotho, F. Becker-Ritterspach, and A. Saka-Helmhout, "Enriching absorptive capacity through social interaction," British Journal of Management, 2011.
Copyright $\odot 2020$ by the authors. This is an open access article distributed under the Creative Commons Attribution License which permits unrestricted use, distribution, and reproduction in any medium, provided the original

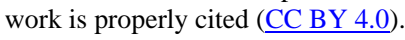

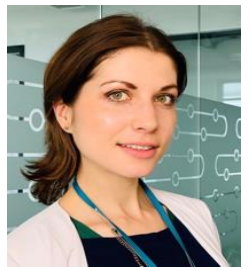

Paulina M. Wojciechowska-Dzięcielak was born in Cracow, Poland in 1992. In 2017 obtained the title of master of economics at University of Wroclaw, at the Faculty of Law, Administration and Economics. In 2015 obtained the engineer's degree in mechanics, at Wroclaw University of Technology in Poland, at the Faculty of Mechanical Engineering, specialization in management and engineering of production. She is currently working and studying at Wroclaw University of Economics doing the research for her $\mathrm{PhD}$ in the field of organizational behavior. 